$5-1990$

\title{
Decentralization and Policy Design
}

University of Pennsylvania

Follow this and additional works at: https://repository.upenn.edu/cpre_policybriefs

Part of the Curriculum and Instruction Commons, Educational Administration and Supervision Commons, and the Education Policy Commons

\section{Recommended Citation}

University of Pennsylvania. (1990). Decentralization and Policy Design. CPRE Policy Briefs.

Retrieved from https://repository.upenn.edu/cpre_policybriefs/62

This document was authored by the Consortium for Policy Research in Education, but no individual authors were identified.

View on the CPRE website.

This paper is posted at ScholarlyCommons. https://repository.upenn.edu/cpre_policybriefs/62

For more information, please contact repository@pobox.upenn.edu. 


\title{
Decentralization and Policy Design
}

\author{
Abstract \\ This brief focuses on design issues surrounding policies aimed at decentralization, drawing from three \\ CPRE reports - Working Models of Choice in Public Education, Richard Elmore; Diversity Amidst \\ Standardization: State differential Treatment of Districts, Susan Fuhrman; and School District \\ Restructuring in Santa Fe, New Mexico, Martin Carnoy and Jean McDonnell. \\ Across the nation, states and school districts are exploring different ways to give schools more \\ autonomy. Proponents of decentralization point to research finds that link school effectiveness to school- \\ level discretion and examples of corporate restructuring where decentralized and simplified \\ administration has increased efficiency. The decentralization movement has also gained momentum from \\ the argument that those who are ultimately responsible for the success of teaching and learning-- \\ teachers, students and parents--need to participate in key school-level decisions about instruction. \\ Disciplines \\ Curriculum and Instruction | Educational Administration and Supervision | Education Policy

\section{Comments} \\ This document was authored by the Consortium for Policy Research in Education, but no individual \\ authors were identified. \\ View on the CPRE website.
}




\section{Decentralization and Policy Design}

Across the nation, states and school districts are exploring different ways to give schools more autonomy. Proponents of decentralization point to research findings that link school effectiveness to school-level discretion and examples of corporate restructuring where decentralized and simplified administration has increased efficiency. The decentralization movement has also gained momentum from the argument that those who are ultimately responsible for the success of teaching and learning - teachers, students and parentsneed to participate in key school-level decisions about instruction.

While support for decentralization is growing rapidly, there is no one "right way" to accomplish it. The different paths to decentralization include choice programs that permit parent and student choice of school and envision market-driven differences from school-to-school, state support for local innovation and experimentation through regulatory flexibility, and district-level decisions to devolve central office functions to the school. ${ }^{1}$

Whatever the approach to decentralization, however, one thing is clear: careful attention must be paid to how policies are designed and how they might interact with the context in which they are embedded if they are to have a chance at producing their intended effects.

This issue of CPRE Policy Briefs focuses on design issues surrounding policies aimed at decentralization, drawing from three new CPRE reports. In Working Models of Choice in Public Education, Richard F. Elmore examines three programs that illustrate different approaches to public school choice. The programs are the Minnesota Post-Secondary Enrollment Options Program (PEO), which allows 11 th and 12th-grade students to enroll in courses in post-secondary institutions; the New York City Community District 4 Alternative School Choice Program, which has evolved over 16 years into a system where one-fifth of the elementary students and all of the junior high school students choose schools that represent a wide choice of educational options; and the Washington State Education Clinics program in which organizations, including private for-profit firms, run remediation programs for young people between the ages of 13 and 19 who have dropped out of school.

In Diversity Amidst Standardization: State Differential Treatment of Districts, Susan H. Fuhrman explores the growing trend of states using performance data to differentiate between districts in compliance and assistance activities. Interviews with agency personnel in 25 states revealed four relatively new forms of differential treatment, which are often used in combination with one another:

1. performance-based accreditation, which adds outcome measures to compliance measures as criteria for district accreditation/certification, expands categories of accreditation status to discriminate more discretely among districts, and varies the degree of oversight based on accreditation status;

2. performance-based rewards and sanctions, which give monetary or non-monetary rewards to higherperforming districts or schools, and applies sanctions (which in at least six states can include intensive state intervention) to lower-performing districts;

3. targeted technical assistance, which channels state agency resources to low-performing districts; and

4. regulatory waivers designed to encourage innovation and provide flexibility to districts and schools.

\footnotetext{
'According to the National Governors' Association, by 1989, 6 states had enacted interdistrict choice options for all K-12 students while another 15 had such policies under consideration; 17 states offered post-secondary enrollment options through which high school students can take college courses for credit at the state's expense; 25 states offered or were planning to offer state funds to local restructuring sites; and 24 states granted or were considering granting waivers to support restructuring (Results in Education 1989, Washington, DC: National Governors Association).
} 
In School District Restructuring in Santa $\mathrm{Fe}$, New Mexico, Martin Camoy and Jean McDonnell examine the implementation of school-level decision making within a single, pioneering district. School Superintendent Edward Ortiz initiated the reform during a period of political stability, drawing on his own prestige and political support and outside assistance from the Matsushita Foundation. Under Ortiz's direction, the district's central administration has been reduced to five key persons: the superintendent, the business manager, an assistant superintendent in charge of elementary curriculum, an assistant superintendent in charge of secondary curriculum, and a director of administrative service in charge of federal programs, grants and teaching interns. Interviewing and hiring of teachers and principals has shifted to the school site; curriculum task forces and school improvement coordinators at each school comprise a districtlevel curriculum council which "reviews and says yes" to individual teacher and school curriculum projects and ideas.

\section{Design Issues in Public School Choice}

Supporters of public school choice argue that increased choice will make the public school bureaucracy more responsive to differences among children and will introduce incentives for improved performance. But public school choice policies involve a number of complex design decisions, each of which raises its own set of problems. Therefore, the test of whether choice policies "work" is not just whether they address problems of responsiveness and performance of public school bureaucracy but whether they solve certain design problems inherent in choice policies.

The first design issue concerns the relationship between demand-side and supply-side choice. Public school choice is usually viewed as an issue of client control; hence policies are addressed first and foremost to enhancing choice for parents in the school assignment of their children. But increasing demand-side choice without also increasing supplyside choice for educators - in what they teach and which schools they affiliate with - can result in predictable problems. For example, if parents and students are encouraged to choose among alternatives that are similar in content and pedagogy, and over which educators exercise little influence, the result is likely to be increased dissatisfaction rather than increased responsiveness.

2 The three cases of choice studied demonstrate the interdependence of supply-side and demand-side policies and the need for a more complete understanding of this relationship.

Demand in these programs is regulated in two ways. In the Minnesota PEO program, the Washington Clinics program, and the elementary school program in District 4 , clients can choose whether or not to participate, whether or not to choose a school. These are "option demand" systems. In the District 4 junior high school program, all clients must choose. This system provides "universal choice."

The cases also represent different approaches to supply-side regulation. The Minnesota PEO program is primarily a demand-side policy which, in effect, delegates supply-side matters of what gets taught to whom to participating secondary and post-secondary institutions on the assumption that they are wellequipped to make judgements of content and quality. Hence, it is not surprising that evaluations of PEO stress how many students choose to take courses in postsecondary institutions rather than what students actually learn in those courses. The policy is well-equipped to influence the former, and not equipped at all to influence the latter.

The Washington State clinics program and the District 4 alternative schools program, in contrast, are designed to actively influence supply as well demand. In the clinics program, supply is influenced by personnel and content controls as well as financial incentives to providers. In the District 4 program, supply is influenced by teacher initiative and central decision making about program quality.

Educational choice policies are frequently seen as "deregulating" mechanisms that substitute the discipline of market incentives for external regulation. These working models of choice demonstrate that the introduction of choice is not really deregulation, but a change in the regulatory regime, or incentive structure, within which schools operate.

The Minnesota case demonstrates that the decision not to regulate the supply side, except by specifying institutions from which students might choose, is, in effect a decision to give those institutions the authority to decide what programs to offer. It is, in other words, a form of supply-side self-regulation. The Washington State and District 4 programs involve significant regulation of both supply and demand, but the resulting in- centive structure under which schools operate in those programs is very different from that under which most schools operate.

A second design issue concerns making choice work for the benefit of all clients, not just those parents and students who already know how to use the system to their advantage. Option demand systems, like the Minnesota PEO and the Washington Clinics, are well-designed to serve active choosers, those who are motivated to choose. The major consequence of this approach is that the programs can be considered "successful" even if they serve only a relatively small proportion of the total pool of eligible clients. In fact, one would not expect such option demand systems to exert great influence on the overall quality of the educational system or on the educational opportunities and performance of the remainder of the client pool. For example, it is likely that the Minnesota PEO program might spur high schools to make small changes on the margins of the curriculum in order to retain the small proportion of active choosers; the program is not likely to lead to major changes in high schools that would affect all students.

Universal choice policies, such as the junior high alternative programs in District 4 , present a much different set of incentives to clients and institutions. If all clients are required to choose among programs when they enter the system, and if there are effective supply-side incentives and regulations to induce quality, then one would expect client choice to have relatively broad effects on clients and institutions. It is more difficult for schools to adapt to universal choice systems with minor changes, since all clients and all institutions are required to choose. However, while universal choice policies attempt to eliminate the distinction between active and inactive choosers at the entry level, the distinction may reappear in the daily operation of schools. Whether clients stay engaged in schooling after they make their initial choice of schools is as much a function of program design and supply-side regulation as it is of initial choice.

A final design issue is the integration of choice programs with existing systems of schooling. The enactment and implementation of the Minnesota PEO and Washington Clinics programs seem to be exercises in the "domestication" of new choice policies by existing political interests and organizational structures. Shifts in enrollment under the two pro- 
grams have been small and high schools seem neither to have been seriously inconvenienced nor to have changed their usual way of doing business in anything other than minor ways. While established educational interests feared these proposals prior to their enactment, their fears seem to be largely unfounded. By the same token, the programs have not had the galvanizing effect on public education that their sponsors hoped they would have.

The District 4 alternative school program is a rather different case. The evidence is strong that the program has significantly changed the operating routines of the community district and schools. On a number of dimensions- school size, the nature of teachers' work in schools, the way individual schools' missions are defined, student and teacher assignment to schools, and the relationship of the community district to schools - District 4 operates differently from other community districts in New York and from other school districts generally. These changes, it is important to note, are the result of dogged persistence over 16 years, a much longer period than most school systems are willing to devote to an educational innovation. It is also important to note, however, that none of the other community districts in New York has undertaken anything as extensive as District 4's system of alternative programs and that the city-wide administration has avoided any suggestion that its experience might be generalized. From the city-wide perspective, then, District 4 looks like another case of the domestication of choice to the existing system, even though its effects are much more extensive when viewed from within.

\section{Design Issues in Programs to Vary Regulatory Treatment}

State efforts to exempt districts or schools from regulation in order to spur innovation are quite new. Traditionally, states have offered to waive certain rules for districts having temporary problems complying with regulation; states have expected eventual compliance and were likely to closely monitor districts with waivers to assure that the expectations were met. Recently, however, a number of states have decided to make waivers available on the assumption that regulations may be inhibiting creative efforts to enhance quality; compliance to the letter of the law is not expected. It is too soon to evaluate the effects of the newer type of regulatory waivers, but several features of the design of regulatory flexibility programs seem key to their potential success.

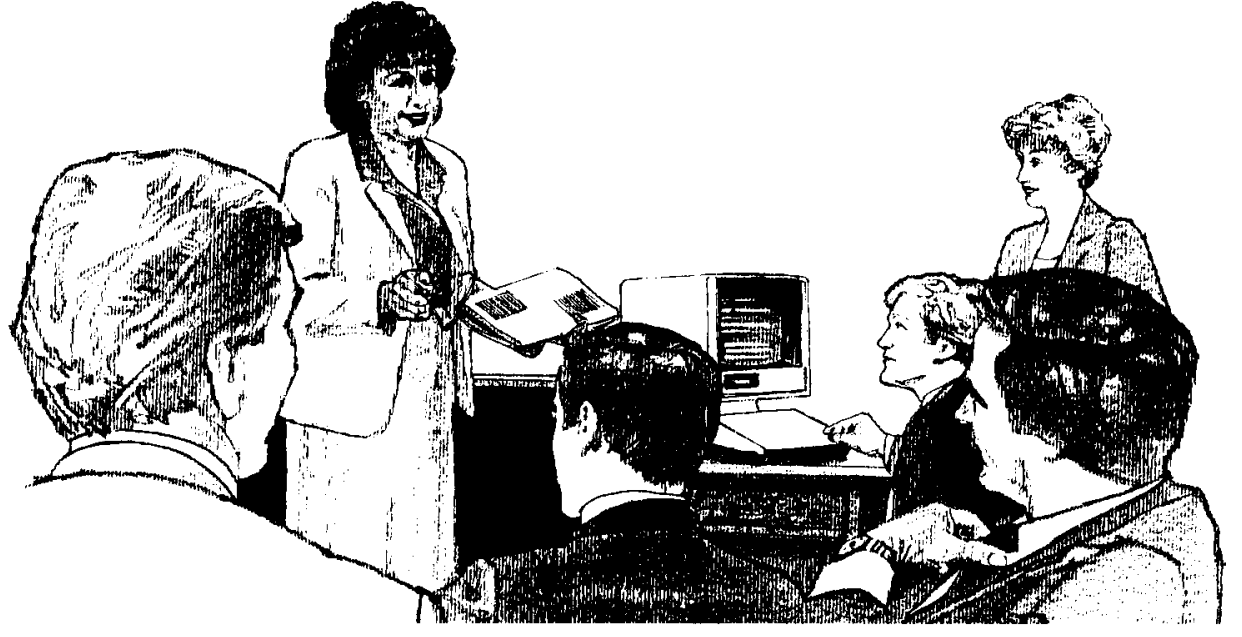

A first design issue concerns eligibility for waivers. A noticeable trend is to make regulatory flexibility available only to districts that perform relatively well on outcome measures. Politically, it is easier to justify exemption for districts that have demonstrated they can provide quality education than to make the case for granting flexibility to districts that have not done well. The latter districts are in fact what state policymakers had in mind when they designed many of the minimal standards that comprise state regulation. However, reserving flexibility for the already well-performing has the effect of removing rules for those who have flourished under them and applying them more stringently to those who have not.

Research on school effectiveness tells us that school-level discretion and collegial determination of school policy are likely precursors to school improvement. The research suggests that some schools in difficulty might benefit from the flexibility to design improvement approaches that meet their needs. Conversely, schools that have done very well under existing regulatory systems might see little need to fix what is not broken by availing themselves of waivers.

The willingness of schools and districts to participate in flexibility programs raises another design issue. Most new approaches consist of rule-by-rule exemption upon district or school request. So far, in states where waivers are offered to participants in pilot restructuring programs or where state agency personnel have urged broader use of waivers, local educators have rarely requested them. Perhaps local educators are more constrained by local interpretation than by state regulation; perhaps they mistrust state officials' promises to foreswear monitoring of waived rules; perhaps they ignore impeding rules in practice. Another possibility, however, is that constraint stems from the accumulated body of rules and regulations taken together or the mindset it creates. If so, waivers of single rules will not help. More sweeping approaches that offer freedom from entire sets of rules may offer greater promise.

Furthermore, it is quite possible that change is more inhibited by tradition and habit than by regulation. Removing rules will not automatically encourage creativity, even though removing the rules does erase some excuses used to reinforce tradition. It may be that local educators will benefit most from flexibility if it is combined with technical assistance about changing authority relationships and models of significantly different approaches to schooling. Deregulation does not mean a diminished role for state education agencies but a shift in focus from compliance to assistance.

As with all education policy, the effects of flexibility provisions also depend on how they interact with the components and goals of other state policies. It would be ironic if the possibility of exempting some schools from rules reinforces the notion that rules are meant only to set minimums. For example, many educators are talking about designing curriculum policies - such as frameworks and assessments - to support more ambitious, sophisticated conceptions of academic content. Such leading-edge standards will not get careful consideration if state standards are designed with only troubled districts in mind. Another irony would occur if flexibility programs aimed at enhancing quality strengthen reliance on standardized tests that drive curriculum to focus on narrow basic skills because performance on those tests is used to identify districts eligible for deregulation.

\section{Design Issues in District Decentralization}

Experiments in devolving authority to the school level are providing many lessons about the components of such approaches. For example, we have learned that in contrast to some experiments with school-based manage- 


\section{Recommended Reading on Restructuring Education}

Decentralized educational governance is often viewed as a key component of plans to restructure schools to better meet the needs of a diverse population. The publications listed below address various issues surrounding the restructuring movement.

See the list of CPRE Publications for information on obtaining the three CPRE reports highlighted in this brief, as well as previously published CPRE reports on restructuringrelated issues such as school-based management and choice in public education.

\section{Restructuring Schools: \\ The Next Generation of Educational Reform}

Richard F. Elmore, editor Available from: Jossey Bass Inc., Publishers, 350 Sansome St., San Francisco, CA 94104 (April 1990, 285 pp., \$28)

This new book, sponsored by CPRE, offers a comprehensive look at the many varied and often conflicting proposals for restructuring schools. In original chapters written expressly for this volume, the authors analyze efforts proposed to address problems such as high teacher turnover, outdated curricula, and unresponsive school bureaucracies. They discuss the resources required to make these efforts successful, the practical issues involved, and implications for administrators, policymakers and teachers.

\section{Early Experience in Restructuring Schools: Voices from the Field ${ }^{\star}$ \\ Richard F. Elmore \\ (1988, 23 pp., \$7.50).}

This essay summarizes major themes and lessons learned about supporting, developing, and implementing education reforms at the state, district and school-building level. Elmore identifies obstacles, both internal and external, to restructuring schools. He also outlines some strategies that have emerged from the early experience of practitioners at the school and district levels and offers guidance to those interested in initiating pilot programs to change the structure of schools.

\section{Restructuring in Progress: Lessons from Pioneering Districts ${ }^{\star}$ \\ Jane L. David \\ (with Stewart Purkey and \\ Paula White) \\ (1989, 47 pp., \$7.50).}

As part of its leadership role in working with states on restructuring initiatives, the National Governors' Association commissioned CPRE to conduct case studies of local school districts experimenting with new structural arrangements. The study team examined four such districts: Jefferson County Public Schools, Louisville, KY; Dade County Public Schools, Miami, FL; Poway Unified Schools, Poway, CA; and New Orleans Public Schools. New Orleans, LA. In order to attach practical meaning to the term restructuring, David describes how these districts have changed their operations. The case studies focus on local initiatives and identify some important lessons for local and state leaders considering similar restructuring efforts.

\section{State Actions to Restructure Schools: First Steps * \\ Jane L. David, \\ Michael Cohen \\ Dean Honetschlager and \\ Susan Traiman \\ (1990, 43 pp., \$7.50).}

This publication includes case studies of early restructuring efforts in five states-Arkansas, Maine, Massachusetts, North Carolina, and Washington. The report describes education initiatives in each state, discusses state efforts to stimulate restructuring, and identifies some important implications of these early experiences. The authors base their findings on interviews conducted in the spring and summer of 1989 . The final chapter includes information from follow-up conversations in January 1990 in its discussion of the immediate and long-term future of restructuring.

*These reports are available from: National Governors' Association. 444 North Capitol St., Washington, DC 20001-1572. ment, restructuring districts view the effort as systemic and comprehensive; restructuring is not simply a new program or approach designed to add to or change part of the system. Districts beginning to restructure recognize the importance of giving school staff the skills, authority and resources to create new roles and environments appropriate to their situations by: (1) significantly increasing school autonomy (coupling school-based management with waivers); (2) extending decision making; and (3) providing more and better opportunities for professional development for teachers and administrators. ${ }^{2}$

Examination of decentralization in Santa Fe highlights the critical ingredient of teacher time. Teachers participate in creating and implementing new curricular and instructional approaches. For example, at Sweeney Elementary School, social studies is now taught to nongraded, multi-age groups of pupils away from their regular teachers for one hour daily. At Kearny Elementary, Spanish, science and social studies are team taught to the first and second grades. One goal is to have children speaking Spanish fluently after spending six years at Kearny. At both schools, all faculty participated in developing these projects.

In addition to greater control over curriculum and delivery, teachers in Santa Fe are also being empowered to select their own school principals and, with their principals, to govern their schools. For example, faculties of the Larragoite Elementary School and the Capshaw Junior High School hired their own principals in 1987-1988, in a long process akin to faculty search committees in universities.

Clearly the process depends largely on the willingness of the superintendent, the school board, and the state legislature to allow teachers to participate in decision making, but it also depends on the volunteerism and idealism of the teachers themselves. Increased teacher control does not mean increased teacher salaries, which in New Mexico's funding system depend on the state budget. Whatever funds have been used to support the school improvement process have come from the outside, primarily the Matsushita Foundation. The bottom line is that Santa Fe's teachers generally have to put in unpaid time for all the participation and planning. For some, the psychic rewards are sufficient; they are excited, although tired. But in other

\footnotetext{
${ }^{2}$ See Jane David, Restructuring in Progress: Lessons from Pioneering Districts (Washington, DC: National Governors Association, 1989).
} 
schools, the psychic reward is not as motivating. Some coordinators stated that they simply didn't have enough time to do all their daily classroom tasks and also meet regularly in the interest of overall school improvement.

One important lesson of the Santa Fe experience is, therefore, that even in a situation where the district office promotes school-based management, the degree of implementation depends on how teachers view the monetary and nonmonetary rewards of their work. Eventually, the volunteer work may be "monetized" into higher teacher salaries, especially if the reform results in greater measurable effectiveness (or even in visibly greater parent satisfaction) that would readily justify higher salaries. If these are refused or are raised less than expectations, psychic reward could turn to psychic disincentive and the reform could disintegrate. If to the contrary, the reform does not result in greater measurable effectiveness, teachers could easily burn out. Therefore, policies to encourage school-based decision making must include support of teacher participation and planning time in their design.

A second lesson from Santa Fe concerns program initiation. The design of policies promoting school-based decision making also must take into account the traditional hierarchical nature of school districts. There must be leadership from the top, at both the central office and the school.

Ortiz's leadership been critical, but the principal's role as initiator within the school also seems crucial. Even activist teachers said they prefer strong, positive leadership from the principal- the kind of leadership that makes teachers confident that they can initiate and carry through changes in curriculum and delivery, and then lets go of the innovating process once the teachers take the responsibility. Principals can either be skilled facilitators or significant obstacles to school-based, teacher-participation management. Those principals who have been hostile to Ortiz's initiatives have successfully hindered activist teachers in their schools despite Ortiz's clear message that teachers should work around obstructionist principals.

Finally, Santa Fe's experience teaches us the importance of parent support. Parental enthusiasm for, or at least tolerance for change, is a significant component of the psychic rewards sustaining professional commitment. In the case of Santa Fe, the issue of parental satisfaction is complicated by the tension be-

tween providing special services to students most at need and satisfying the most vocal parents whose children often are not the neediest. For example, Sweeney elementary developed a pilot summer program for at-risk pupils, supported by an outside grant and teacher fundraising. The program gave participants the opportunity to take leadership roles in a multi-age setting; it received high praise from parents, pupils and teachers. However, the success of the summer school resulted in parents of already successful pupils demanding that their children be able to participate with the at-risk students in a similar program the next year. The effort to focus innovative activities and other resources just to at-risk students is thus compromised by pressures from vocal, already highly participative parents who know how to get the best the schools can offer for their children.

\section{The Center for Policy Research in Education (CPRE)}

CPRE unites four of the nation's leading research institutions in a unique venture to improve the quality of schooling. CPRE conducts research on the implementation and effects of state and local education policies. By communicating its findings to policymakers and practitioners, the Center contributes to the framing of policies to improve education. Members of the CPRE consortium are: Rutgers, The State University of New Jersey; Michigan State University; Stanford University; and the University of Wisconsin-Madison. CPRE is sponsored by the Office of Research in the Department of Education's Office of Educational Research and Improvement (OERI).

\section{CPRE'S}

\section{research activities}

are concentrated in five major areas:

\section{- Curriculum and Student Standards}

- Teacher Policies

- Educational Indicators and Monitoring

- New Roles and Responsibilities

- Evolution of the Reform Movement
In addition to conducting research in these areas, CPRE publishes research reports, briefs and case studies on a variety of education issues. ${ }^{*}$ The Center also sponsors invitational policy workshops for state and local policymakers.

For further information on CPRE, contact: Lynn McFarlane, Assistant Director for Communications, CPRE, Eagleton Institute of Politics, Rutgers-The State University of New Jersey, New Brunswick, NJ 08901; phone (908) 828-3872.

*The views expressed in CPRE publications are those of individual authors and are not necessarily shared by CPRE, its institutional members or the U.S. Department of Education.

\section{CPRE Management} Director

Susan Fuhrman

Eagleton Institute of Politics

Rutgers, The State University

of New Jersey

\section{Management Committee}

William Clune

Wisconsin Center for

Education Research

University of Madison-Wisconsin

Richard Elmore

College of Education

Michigan State University

Marshall Smith

School of Education

Stanford University 